\title{
Cloning and Characterization of a PI-like MADS-Box Gene in Phalaenopsis Orchid
}

\author{
Bin Guo ${ }^{1}$, Saiyin Hexige ${ }^{1}$, Tian Zhang ${ }^{1}$, Jon K. Pittman ${ }^{2}$, Donghong Chen ${ }^{1}$ and Feng Ming,* \\ ${ }^{1}$ Institute of Genetics, State Key Laboratory of Genetic Engineering, Research Center of Gene Diversity and Designed Agriculture, \\ Ministry of Education Key Laboratory for Biodiversity Science and Ecological Engineering, School of Life Science, \\ Fudan University, Shanghai 200433, China \\ ${ }^{2}$ Life Sciences, University of Manchester, 3.614 Stopford Building, Oxford Road, Manchester M13 9P, UK
}

Received 16 March 2007, Accepted 24 May 2007

\begin{abstract}
The highly evolved flowers of orchids have colorful sepals and fused columns that offer an opportunity to discover new genes involved in floral development in monocotyledon species. In this investigation, we cloned and characterized the homologous PISTALLATA-like (PI-like) gene PhPI15 (Phalaenopsis PI STILLATA \# 15), from the Phalaenopsis hybrid cultivar. The protein sequence encoded by PhPI15 contains a typical PI-motif. Its sequence also formed a subclade with other monocot PI-type genes in phylogenetic analysis. Southern analysis showed that PhPI15 was present in the Phalaenopsis orchid genome as a single copy. Furthermore, it was expressed in all the whorls of the Phalaenopsis flower, while no expression was detected in vegetative organs. The flowers of transgenic tobacco plants ectopically expressing PhPI15 showed male-sterile phenotypes. Thus, as a Class-B MADS-box gene, PhPI15 specifies floral organ identity in orchids.
\end{abstract}

Keywords: In situ hybridization, MADS-box gene, Phalaenopsis orchid, PI

\section{Introduction}

The transition from vegetative to reproductive phase is one of the most critical developmental events in the life of a plant. The initiation of flowering and the establishment of the floral organs are controlled by several genes in addition to environmental factors. Genetic and molecular analysis of homeotic mutants of Arabidopsis and Antirrhinum has led to the identification of genes involved in floral development and

\footnotetext{
*To whom correspondence should be addressed.

Tel: 86-21-55665397; Fax: 86-21-65648376

E-mail: fming@fudan.edu.cn
}

the establishment of the classical floral ABC model (Bowman et al., 1991; Coen et al., 1991; Davies et al., 1994; Weigel et al., 1994). Most of these genes have a consensus domain named MADS-box, which was named after four members of the family: $\underline{M C M 1}$ (yeast), $\underline{A}$ GAMOUS (Arabidopsis), $\underline{D} E F I C I E N S$ (Antirrhinum) and $\underline{S} R F$ (human). Since the first plant MADSbox gene, DEF (DEFICIENS), was cloned from Antirrhinum in 1990 (Sommer et al. 1990), most studies have concentrated on the model species Arabidopsis and other dicotyledonous species.

Plant MADS-box genes can be divided into several groups according to sequence similarity, expression patterns and function. Almost all MADS-domain proteins known from vascular plants share a conserved structural organization referred to as a MIKC-type domain structure (Kim et al., 2004). In the classic "ABC" model of flower formation, the four floral components are controlled by the interactions of three classes of floral MADS-box genes: A, B, and C (Weigel et al., 1994). A-functional genes regulate the formation of the sepal; A-functional and B-functional genes together control the formation of the petal; B-functional and C-functional genes together regulate the stamen development; and Cfunctional genes alone control the carpel formation. Studies based on Arabidopsis have revealed that APETALA1 (APl) and APETALA2 (AP2) are A-functional genes; APETALA3 $(A P 3)$ and PISTILLATA (PI) are B-functional genes; and $A G A M O U S(A G)$ is a C-functional gene. These genes are all members of the MADS-box gene family except $A P 2$ (Riechmann et al., 1997). Class-B MADS-box genes are classified into two subclades, PI-type and AP3-type (Theissen et al., 2000), on the basis of a different motif at the $\mathrm{C}$ terminal of the amino acid sequence; these genes play an important role in petal and stamen identity.

In contrast to the well-studied dicotyledonous plants such as Arabidopsis and Antirrhinum, relatively few genes controlling the flower development of monocot species have been 
identified and characterized (Petersen et al., 2004). However, the fact that MADS-box genes also function in monocotyledons is a source of great interest for at least two reasons: the structural diversity of their flowers and inflorescences, and the commercial importance of their flowers, seeds, and fruits (Theissen et al., 2000).

Phalaenopsis is a member of the Orchidaceae, one of the largest flowering plant families. Commercially, Phalaenopsis plays a very important role in the world flower market. But compared with other plants, little research on MADS-box genes has been reported. Unlike dicotyledonous flowers, all orchid flowers have colored sepals. The sepals and petals of orchid are called tepals because of their similar color and shape. The median tepal in the inner whorl generally differs from the rest of the tepals and is therefore named the labellum or lip. In addition, the stigma and stamens are always fused to form another specialized structure, a highly modified column. The unique floral morphology has made orchid an attractive model for botanists. In this paper, we cloned a PI-like cDNA from Phalaenopsis and studied its expression and putative function.

\section{Materials and Methods}

Plant material. Young Phalaenopsis plants one year after germination were grown in a greenhouse under natural light and controlled temperature $15^{\circ} \mathrm{C} / 10^{\circ} \mathrm{C}$, Day/Night for two weeks; then, the temperature was changed to $20^{\circ} \mathrm{C} / 15^{\circ} \mathrm{C}$ (Day/Night) to induce peduncle formation, and the initiation of the peduncle could be seen. For RT-PCR and Southern analysis, leaves, stems, bulbs and floral organs (sepal, petal, lip and column) were frozen in liquid nitrogen immediately after collection and stored at $-80^{\circ} \mathrm{C}$. The top of the peduncles were immersed into $4 \%$ paraformaldehyde (PFA) for in situ hybridization.

Wild-type and transgenic tobacco were grown on MS agar medium. One hundred $\mathrm{mg} / \mathrm{l}$ kanamycin was used to select the transgenic tobacco. The young tobacco was transferred onto wet gauze after rooting and was then grown in a greenhouse under natural light and controlled temperature $25^{\circ} \mathrm{C} / 20^{\circ} \mathrm{C}$, Day/Night.

\section{Isolation of MADS-box gene}

Total RNA from the petal was extracted using Trizol (Sangon, China). Primer B26 5'-GACTCGAGTCGACATCGAT $17-3$ ' (Jia et al., 2000) was used for first strand cDNA synthesis (RevertAid ${ }^{\mathrm{TM}}$ First Strand cDNA Synthesis Kit, Fermentas). PCR amplification was performed under the following conditions: $5 \mathrm{~min}$ at $94^{\circ} \mathrm{C}$ for initial denaturation, $30 \mathrm{~s}$ at $94^{\circ} \mathrm{C}, 60 \mathrm{~s}$ at $55^{\circ} \mathrm{C}$ and $90 \mathrm{~s}$ at $72^{\circ} \mathrm{C}$ for 30 cycles, followed by an extension for $10 \mathrm{~min}$ at $72^{\circ} \mathrm{C}$ using the $5^{\prime}$ primer 5'-ATGGG(G/A)G(C/A)GG(C/A)AAG(C/A)AAGAG(C/A) GAGATCAAG(A/C)-3' and the 3' primer 5'-ACTCGAGTCGACA TCGA-3'.

PCR products were cloned into the pGEM-T vector (Promega, USA) for identification and sequencing.

The deduced amino acid sequence of PhPI15, along with other class-B group MADS-box genes, was aligned using the computer program CLUSTAL W (www.ebi.ac.uk/clustalw). A phylogenetic tree of several known B-class genes was constructed using the Neighbor-Joining method provided by the computer program Mega 3 (Kumar et al., 2004). Bootstrap support is indicated on branches. GenBank/EMBL/DDBJ database accession numbers are as follows: PhPI15 (this study, AY771992), PI (D30807), AP3 (D21125), GLO (X68831), DEF (X52023); pMADS2 (X69947), GP (X69946); OsMADS2 (L37562), OsMADS4 (L37527); ZMM16 (AJ292959), ZMM18 (AJ292960), ZMM29 (AJ292961), SILKY1 (AF077760); OrcPI (AB094985); pAP3 (AY771993), PeMADS2 (AY378149), PeMADS3 (AY378150), PeMADS4 (AY378147), PeMADS5 (AY378148), PeMADS6 (AY678299); HPII (AF134114); WPII (AB107991); SmPI (AF230712), SmAP3 (AF230705).

Genomic Southern blot analysis. Total genomic DNA was isolated from the young leaves of Phalaenopsis using SDS buffer (Tris- $\mathrm{HCl} 10 \mathrm{mM}$ pH 8.0, $\beta$-Mercaptoethanol 2.2\% (w/v), $\mathrm{NaCl}$ $500 \mathrm{mM}$, EDTA $20 \mathrm{mM}$, SDS $1.5 \%$ ) following the method described by Murray (Murray, 1980). Fifteen mg of total DNA was digested with DraI or HindIII. The digested DNA was then run on a $0.7 \%(\mathrm{w} / \mathrm{v})$ agarose gel and transferred to a Hybond- $\mathrm{N}^{+}$membrane (Amersham Biosciences). The 3' UTR sequence of PhPI15 was used as the probe and labeled as described by the Gene Images Random Prime Labeling Protocol (Amersham Biosciences). Southern blot analysis was carried out according to the protocol of Gene Images Random Prime Labeling Module and Detection System (Amersham Biosciences). Hybridization was performed at $60^{\circ} \mathrm{C}$ and Hybond- $\mathrm{N}^{+}$membrane was strictly washed three times with $1 \times, 0.5 \times$ and $0.1 \times$ washing solution.

\section{$R T-P C R$}

Total RNA was extracted from the peduncle at various developmental stages, as well as from the bud, root, leaf, sepal, petal, labellum, pistil and stamen of the plant. After determining the $\mathrm{OD}_{260}$ of the samples, $1 \mu \mathrm{g}$ of total RNA was used to synthesize first-strand cDNA using the polyA tail primer $\mathrm{B}_{25}$ and a RevertAid ${ }^{\mathrm{TM}}$ First Strand cDNA Synthesis Kit (Fermentas). This cDNA served as a template in PCRs carried out as described above, using genespecific primers. The primers of orchid actin-F 5'-TGGAACTGCC AAGACG-3', and actin-R 5'-GCAGCGAAGATTCAAAA-3' were used for control amplification.

\section{In Situ Hybridization}

The temporal and spatial expression patterns of PhPI15 transcripts were determined by RNA in situ hybridization. To prevent crosshybridization to the RNA products of other MADS-box genes, the 293 bp 3' region of the PhPI15 cDNA was cloned into the pGEM T-vector (Promega) and this plasmid was used as a template for synthesizing single-stranded RNA. The plasmid was linearized with ScaI in order to generate an antisense probe by in vitro transcription with T7 RNA polymerase using a DIG RNA labeling kit (Roche).

Inflorescences containing floral buds were fixed in 4\% PFA (w/ v). The tissues were subsequently dehydrated and embedded in paraffin according to the modified method of Jackson (1991) (Caliskan et al., 2004). The samples were sliced into $10-\mu \mathrm{m}$ sections. Digoxygenin-UTP labeled antisense RNA probes were transcribed using T7 polymerase (Roche DIG RNA Labeling Kit). After 
deparaffination by treatment with xylene, the sections were treated for $30 \mathrm{~min}$ with proteinase $\mathrm{K}(10 \mu \mathrm{g} / \mathrm{ml})$. Hybridization of the sections was performed at $50^{\circ} \mathrm{C}$ for $16 \mathrm{~h}$. The washes, blocking, antibody incubation and detection were performed according to the procedure for In situ hybridization to Chromosomes, Cells, and Tissue Sections (Roche). Slides were photographed on a microscope using bright-field optics.

Production of transgenic plants. The cDNA fragment of PhPI15 in pGEM T-vector was amplified using the 5' primer 5'-GC TCTAGAATGGGGCGCGGCAAGAT-3' and the 3' primer 5'CGAGCTCTTACTTATTTCGCAA-3'. The restriction sites XbaI and $\mathrm{SacI}$ (underlined) were designed into the $5^{\prime}$ and $3^{\prime}$ primers respectively. The amplified fragment containing the ORF of $\mathrm{PhPI15}$ was cloned into the binary plant transformation vector pBI2301M using the $X b a \mathrm{I}$ and SacI restriction sites. This vector contained the NPTII gene for kanamycin selection of putative transgenic plants. The vector containing $35 \mathrm{~S}:: P h P I 15$ was introduced into the Agrobacterium strain EHA105 by the heat shock method.

Transformations of Nicotiana tabacum cv. Xanthi leaf discs were performed using the Agrobacterium tumefaciens strain EHA105mediated leaf disc transformation method (Horsch et al., 1985). 50 $\mathrm{mg} / \mathrm{l}$ kanamycin (Sangon, China) and $250 \mathrm{mg} / \mathrm{l}$ ceflazidim (Sangon, China) were used for the selection of transformed plants and for removing A. tumefaciens, respectively. All observed phenotypes were heritable and segregated as dominant traits. Morphological analysis was performed on the $T_{1}$ generation.

Pollen Germination. Pollen was isolated from mature flowers by gently releasing them from the anther locules into $17 \%(\mathrm{w} / \mathrm{v})$ sucrose. The liberated pollen was then placed onto plates of pollen germination medium, consisting of $30 \%(\mathrm{w} / \mathrm{v})$ sucrose, $1 \mathrm{ppm} 6-$ benzyl aminopurine (Sangon, China), $0.1 \mathrm{ppm} \alpha$-naphthaleneacetic acid (NAA), $1.6 \mathrm{mM} \mathrm{H}_{3} \mathrm{BO}_{3}$, $\mathrm{pH} 5.8$, and solidified with 5\% (w/v) agar. Pollen was incubated for $5.5 \mathrm{~h}$ at $25^{\circ} \mathrm{C}$ for the analysis of pollen tube formation.

\section{Results}

Isolation of a new Phalaenopsis MADS-box gene. Because the MADS domain is highly conserved among the different members of this gene family, it is possible to isolate additional MADS-box genes by RT-PCR. Degenerate oligonucleotides against this region were designed and PCR was carried out. DNA sequence analysis showed that one of the obtained cDNA sequences, named PhPI15 (874 bp), contains a putative ORF (217 aa), a 3' untranslated region and a poly(A) tail. The sequence was deposited in GenBank under the accession number AY771992. PhPI15 shows 58\% amino acid sequence identity with PISTILLATA from Arabidopsis (Krizek et al., 1996), and $75 \%$ amino acid sequence identity with the MADS-box containing protein PI from Chloranthus spicatus (Kramerand and Irish, 2002). The deduced amino acid sequence alignment with other MADS-box proteins demonstrated that PhPI15 has the typical MIKC-type domain structure and the highly conserved PI sequence motif (MPFxFRVQPxQPNLQE) within the C-terminal region (Fig. 1).

To determine the phylogenetic relationships between PhPI15 and other B-class MADS-box genes, a phylogenetic tree was constructed using full-length amino acid sequences. The tree shows that the class-B gene family can be divided into PI-type and AP3-type clades, and both clades could be separated into dicot and monocot sub-clades. The topology of the phylogenic tree showed that the Phalaenopsis PhPI15 gene was classified into the subclade of monocot PI-type genes (Fig. 2), and also formed a monophyletic subclade with the other B-class genes from monocots.

Genomic Southern blot. Southern blot analysis was carried out to assess the copy number of PhPII5 in the Phalaenopsis genome. To avoid cross hybridization, the probe used was against the 3' region of PhPI15 (Fig. 3A), which is not conserved amongst PI-type genes. The genomic DNA was digested with DraI and HindIII. Our results show that PhPII 5 is present as a single copy in the Phalaenopsis genome (Fig. 3B).

\section{Expression of PI-like MADS-box genes}

RT-PCR analyses were used to examine the specific expression of PhPI15 in different plant tissues, specifically roots, leaves, buds and the tip of the peduncle at different developmental stages and different floral organs in a mature flower (Fig. 4). The result showed that this gene was not expressed in the vegetative phases. It was expressed in the reproductive phase and expressed in all the floral organs of the Phalaenopsis flower (Fig. 5).

\section{In Situ-Hybridization Analysis}

To determine the temporal and spatial patterns of expression of PhPI15, we analyzed RNA accumulation in inflorescences by in situ hybridization. Digoxigenin (DIG)-labeled antisense RNA probes corresponding to the 3' end of PhPII5 (without MADS-box region) were used.

Phalaenopsis has an indeterminate inflorescence meristem from which the floral meristem initiates on the flanks (Yu and Goh, 2000). The development of the floral bud can be divided into three stages: evocation of the inflorescence meristem (stage 1), differentiation into flower primordium (stage 2), and the initiation of sepal, petal and column primordium in the floral meristem (stage 3).

PhPI15 transcript was first detected in the floral bud in which the first floral primordium emerged on the flank of the apical meristem (Fig. 6A). The expression of PhPI15 was present throughout the inflorescence and the floral primordium, while no significant signal was detected in the bract primordium. With the developing of the inflorescence and the floral primordium, the floral buds emerged, and PhPI15 was expressed in all of the floral organs primordium, including sepals, petals, column in addition to the basal floral meristem (Fig. 6C). Stronger expression of PhPII5 was observed on the column (Fig. 6E). Relatively strong signals were detected in the maturing pollinarium, but no significant signals could be 

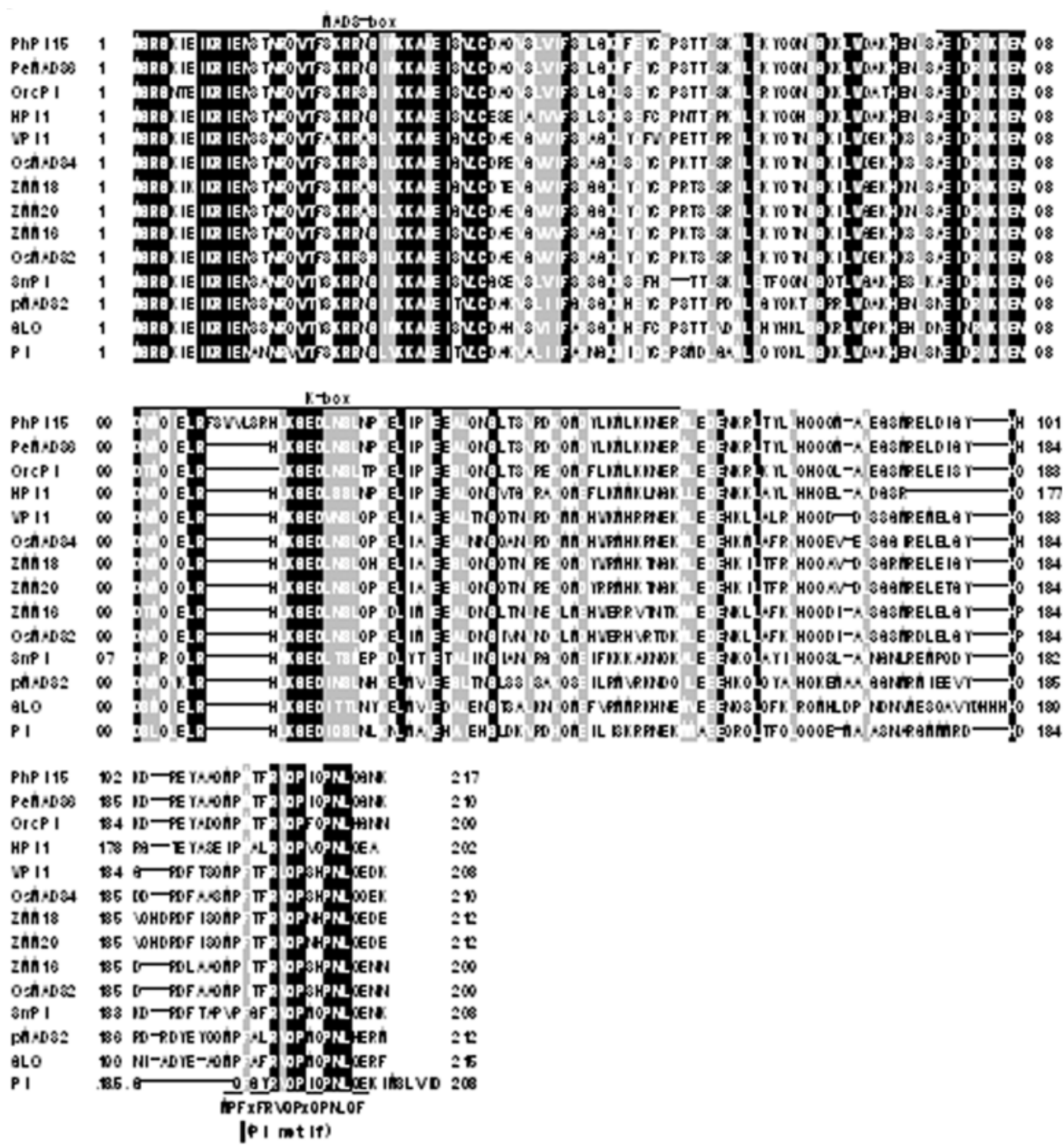

Fig. 1. Comparison of the deduced amino acid sequences of PhPI15 with other PI-type MADS-box proteins. Sequences were taken from the NCBI database and aligned using the computer program DNassist. Dark and gray residues with green indicate amino acid residues identical in all sequences. A dash indicates a gap inserted to maximize alignment. Solid and broken lines indicate the MADS-box and K-box regions, respectively. The PI motif (MPFxFRVQPxQPNLQE) found in the C-terminal region of the PI family is indicated by a black line. The first 10 amino acid residues were used for the PCR-primer design.

observed in the anther cap (Fig. 6G). No expression was observed when the slides were hybridized with sense probe (Fig. 6B, D, F and H).

Ectopic expression of PhPI15 in tobacco. To determine the potential role of PhPI15 in floral development, the PhPI15 gene was ectopically expressed in tobacco through Agrobacteriummediated transformation. Nine out of 16 (about 60\%) independent kanamycin-resistent $\mathrm{T}_{1}$ tobacco plants expressing PhPI15 showed some modifications in the third whorl, and were not coincident with the phenotype of $35 \mathrm{~S}:$ :GLO transgenic tobacco, which showed obvious changes in the first and fourth whorls (Davies et al., 1996). The transgenic tobacco plants (PhPI15s) showed reduced size compared with wild-type plants, when both have flowers (Fig. 7A, B). The carpels of PhPI15 trangenic plants were much longer than the tubes and can be seen in the floral bud when it is not opened, in contrast to the wild type carpel, which can be enveloped by the floral bud (Fig. 7C, D). The stamens of the transgenic (PhPI15s) flowers were much shorter than the pistils, compared with wild-type plants (Fig. 8C-F). The anthers of the PhPI15s flowers had little or no pollen. The average length of the flower tube of PhPI15s (average $3.0 \mathrm{~cm}$ ) was shorter than those of wild-type plants (average $5.2 \mathrm{~cm}$ ) (Fig. 8B). To test the fertility of the transgenic plant pollen, we investigated the germination of pollen from the PhPI15s plants in vitro. It was observed that pollen grains from the PhPI15s plants did not germinate and produced no pollen tubes, unlike wild-type 

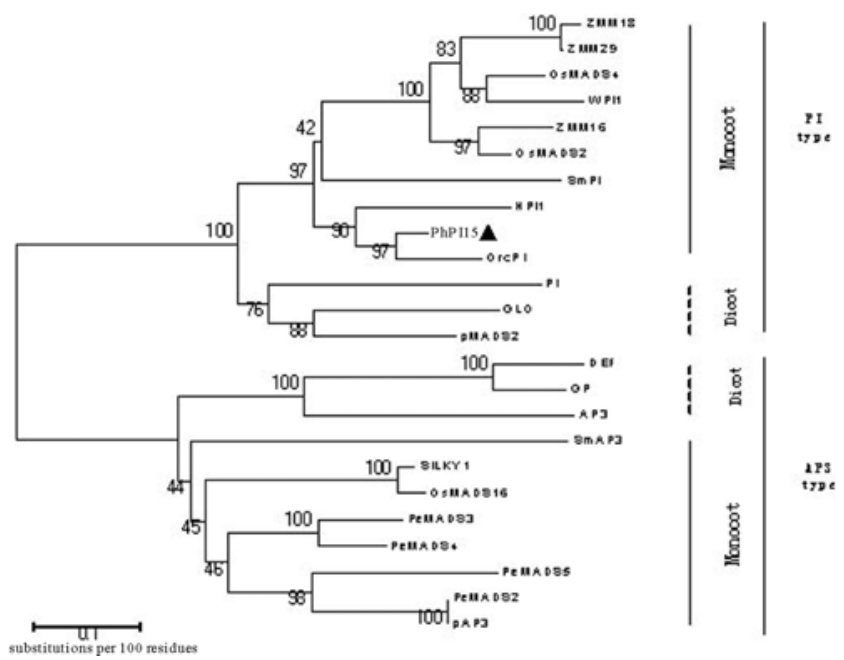

Fig. 2. Phylogenetic analysis of plant class-B MADS-box genes. The amino acid sequences were aligned using the computer program CLUSTAL $\mathrm{W}$, and the dendrogram was then obtained using the neighbor-joining method. PhPII5 is highlighted with a triangle

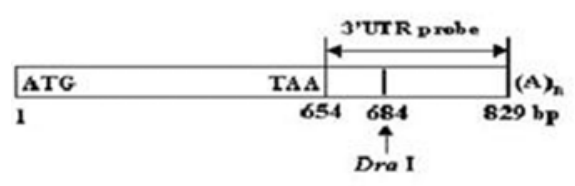

(A)

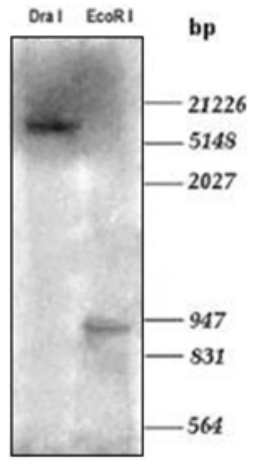

(B)
Fig. 3. Southern blot analysis of Phalaenopsis genomic DNA. (A) A sketch map of the probe. (B) DNA was digested with DraI or HindIII and separated on a $0.7 \%$ agarose gel. The numbers at the right indicate DNA size markers. Southern blots were probed with the 175 bp 3' UTR fragment of DNA (excluding the polyA tail).

pollen under the same condition (Fig. 8G, H). Transgenic tobacco with the empty vector did not show any obvious change in phenotype and its pollen germinated normally, suggesting that ectopic expression of PhPI15 caused malesterility in transgenic tobacco plants.

\section{Discussion}

Orchidaceae is the largest angiosperm family among more than 20,000 species. It came into being one hundred and twenty million years ago. The highly evolved orchid flower is unique to the well-known monocots, which also include maize and rice whose highly reduced flowers make them

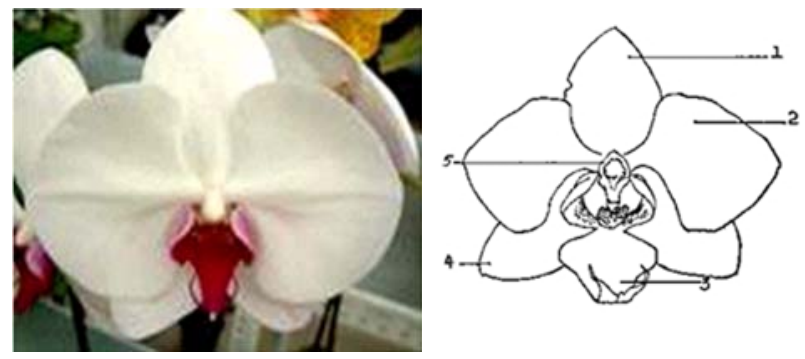

Fig. 4. The overall morphology of wild-type flowers is shown in the photographs on the left and schematically depicted in the floral diagram shown on the right. 1, dorsal sepal; 2, petal; 3, labellum; 4, lateral sepals; 5 , column (fused structure of stamen and pistil).

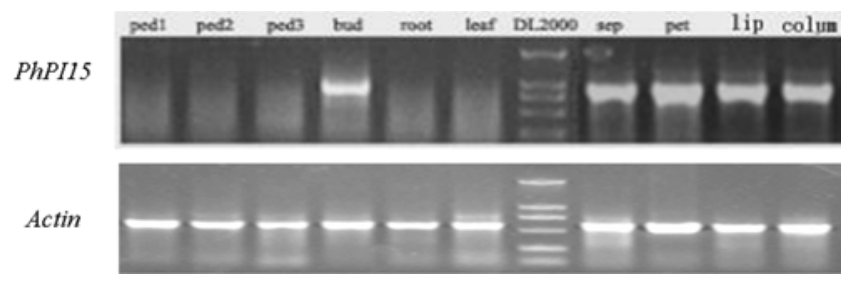

Fig. 5. Expression patterns of PhPI15. Total RNA was isolated from the peduncle in different development stages, from bud, root, leaf and different floral organs. Actin was used as a control. ped 1: peduncle with two nodes, ped 2: peduncle with three nodes, ped 3: peduncle with four nodes, sep: sepal, pet: petal, lip: labellum, column: fused stamen and pistil. Marker DL2000 sizes are: 2000, $1000,750,500,250$, and $100 \mathrm{bp}$ from the top. RT-PCR analysis was replicated twice with similar results.

unsuitable for the study of flower development. All flower structures except whorls are present in orchids, and the highly sophisticated flower organization offers an opportunity to discover new variant genes and different levels of complexity within morphogenetic networks (Tsai et al., 2004). Study of the flower development of orchids not only can test the validity of the classical $\mathrm{ABC}$ model in monocots, but can also allow investigation of the roles of MADS-box genes involved in the patterning of this highly structured flower and may help increase our understanding of the evolution of orchid species.

It should be noted that although floral organ identity MADSbox genes have been well studied in Arabidopsis and Oryza sativa, no such homology has been identified in orchid. To date, four orchid members of the APETALA1/AGL9 subfamily of the MADS-box genes have been identified in Aranda $c v$ DEboran and Dendrobium cv Madame Thong-In (Lu et al., 1993; Yu and Goh, 2000). Four members of the AP3/DEL subfamily genes have been identified in Phalaenopsis orchid (Tsai et al., 2004). A $P I / G L O$ subfamily gene and two AGAMOUS-like genes have also recently been identified in Phalaenopsis (Tsai et al., 2005; Kanno et al., 2005). The study of their expression patterns showed that these genes are important in the regulation of floral transition and organ identity.

The MADS-box gene PhPI15 we isolated from Phalaenopsis 

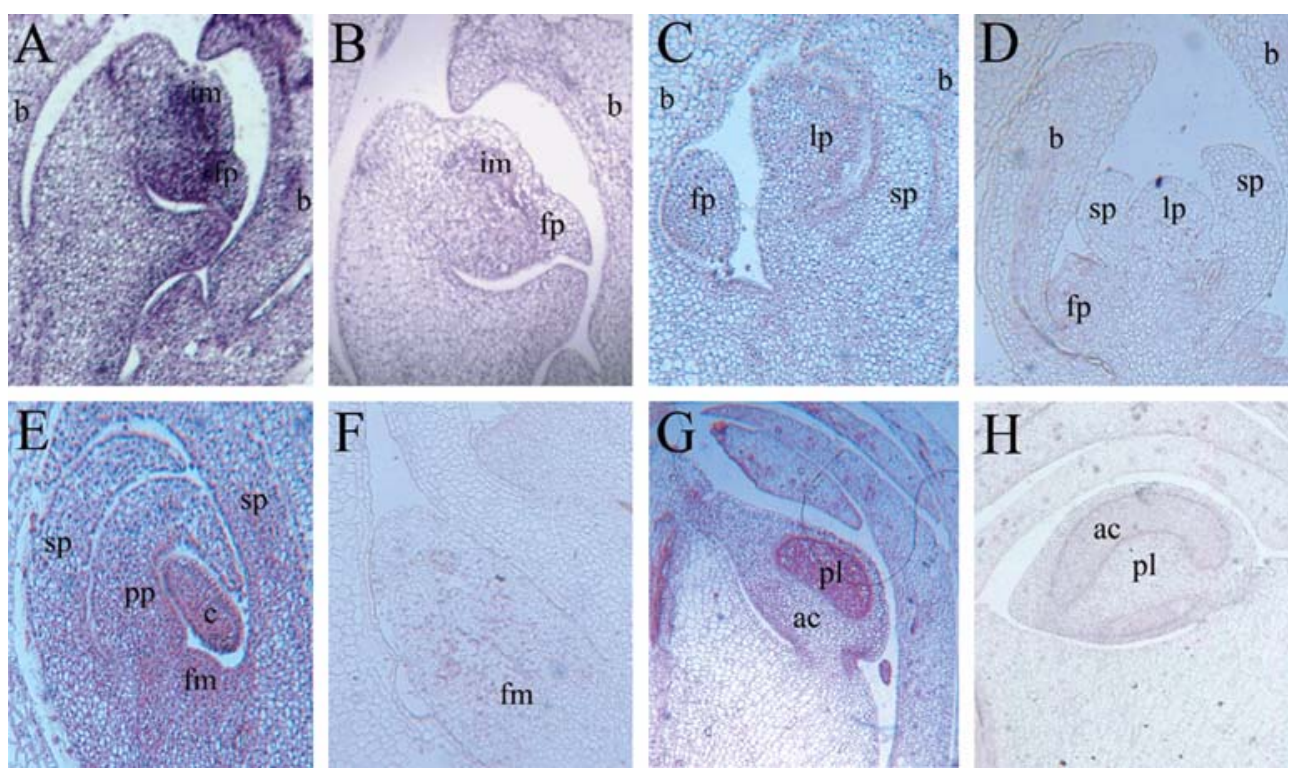

Fig. 6. In situ localization of PhPI15 transcripts in longitudinal sections in developing floral buds. Sections were hybridized with the antisense 3'-specific RNA probe (A, C, F, G) or the sense 3'-specific RNA probe (B, D, F, H). A, shoot apical meristem with the infloresence meristem and the initiation of the first floral primordium (magnification, $\times 100$ ). $\mathrm{C}$, shoot apical meristem with the infloresence meristem and the developing floral organ primordium (magnification, $\times 200$ ). E, the young developing floral bud with all of the floral organ and the basal floral meristem (magnification, $\times 160$ ). G, the mature flower with the pollinarium (magnification, $\times 40$ ). ac, anther cap; b, bract; c, column; fm, floral meristem; fp, floral primodium; im, inflorescence meristem; lp, lip primordium; pp, petal primordium; pl, pollinarium; sp, sepal primordium.

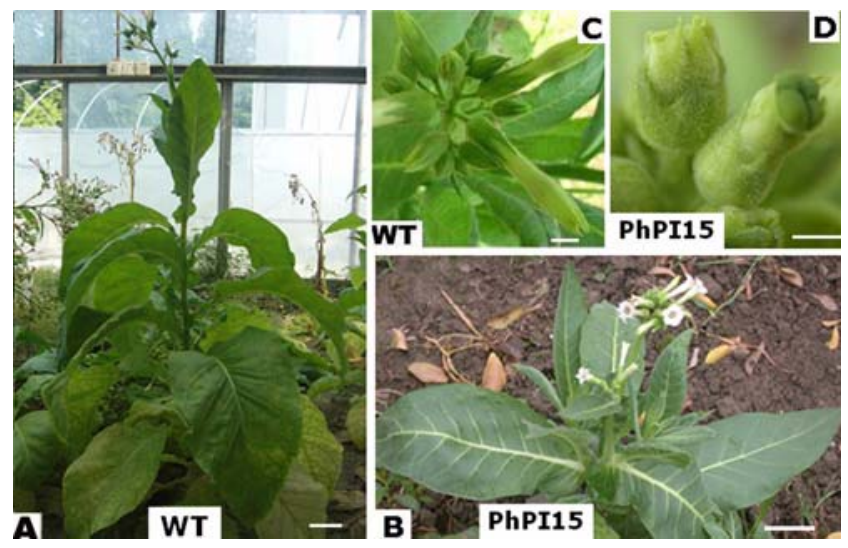

Fig. 7. (A)-(D), Over-expression of PhPI15 in tobacco plants changed flower development. A, Plant morphology of wild-type tobacco $($ bar $=10 \mathrm{~cm})$; B Plant morphology of 35S::PhPI15 tobacco $(\mathrm{bar}=10 \mathrm{~cm}) ; \mathrm{C}$, The inflorescence of wild-type tobacco $(\mathrm{bar}=$ $0.5 \mathrm{~cm})$; D, The inflorescence of $35 \mathrm{~S}::$ PhPI15 tobacco $(\mathrm{bar}=0.5 \mathrm{~cm})$; the carpel can be seen at the top of the floral bud.

hybrid cultivar is unique among reported MADS-box genes, but shows high sequence similarity to Arabidopsis B class MADS-box gene PISTILLATA (Goto and Meyerowitz, 1994). The deduced amino acid sequence showed that it has a typical MIKC domain structure. It showed a high homology to other PI-type MADS-box genes of other monocot plant species. This suggested that PhPII5 is the putative PI homologue from
Phalaenopsis. This assumption was also supported by the observations that in the C-terminal region of the deduced amino acid sequence of PhPI15, there is a consensus PI motif (Fig. 1) observed in other PI-type MADS-box genes (Kramer et al., 1998; Hama et al., 2004). Among plant MADS proteins, Asp-98 is conserved in the PI and AP3 subfamilies and is critical for the AP3/PI interaction (Kramer and Irish, 1999; Yang et al., 2003). This residue is also present in PhPI15 (Fig. 1).

Phylogenetic analysis further confirmed this orchid MADSbox gene belongs to PI-lineages. PhPI15 falls into the clade of PI-like genes in the phylogenetic tree constructed with other known B function genes (Fig. 2). Within the clade of monocot PI-like proteins, PhPI15 and PeMADS6 from Phalaenopsis, and OrcPI from Orchis italica (NCBI database), constituted a well-supported subclade that excludes members of the Poaceae family. This suggests that the common ancestor of Orchidaceae might have two PI-like genes.

The results of RT-PCR illustrated that PhPI15 is only expressed in flower organs and not in vegetative tissues of the plant (Fig. 5). This expression pattern is similar to those of PeMADS6 (Tsai et al., 2006) and DcoPI (Xu et al., 2006) from orchid. This suggests that $P h P 115$ may only be involved in floral development. Unlike other B group MADS-box genes in dicotyledonous species, which are only expressed in the second, third and fourth whorls of developing flowers (Goto and Meyerowitz, 1994), PhPI15 was expressed in all of the whorls of Phalaenopsis flowers (Fig. 5). This may be 

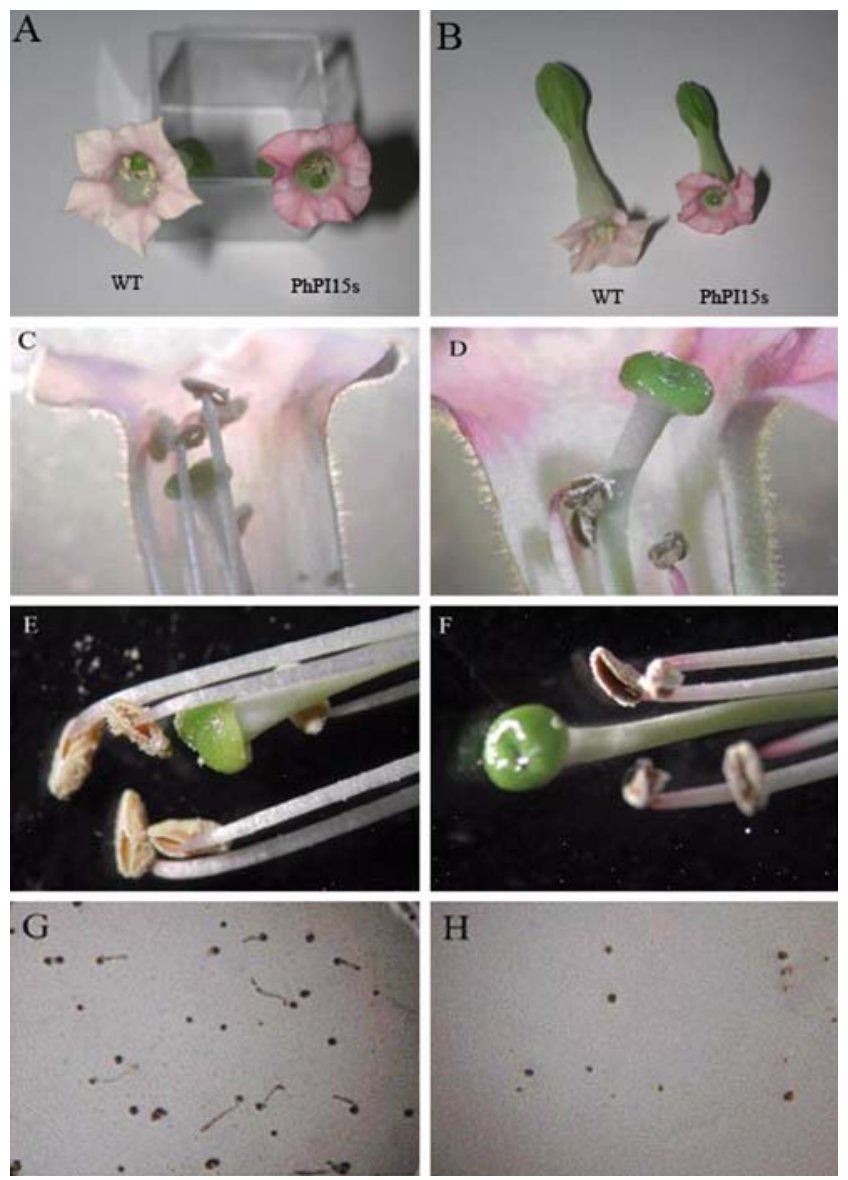

Fig. 8. (A)-(H), Morphological changes in transgenic tobacco flowers ectopically expressing PhPI15. A, top view of wild-type (wt) and transgenic tobacco flowers (PhPI15s). B, side view of wild-type (left) and transgenic tobacco flowers (right). C and D, straight-cut of wild-type and transgenic tobacco flowers (magnification, $\times 10$ ). $\mathrm{E}$ and $\mathrm{F}$, the stamen and pistil of wild-type and transgenic tobacco flowers (magnification, $\times 20$ ). $\mathrm{G}$ and $\mathrm{H}$, wild-type and transgenic pollen after $5.5 \mathrm{~h}$ on germination medium (magnification, $\times 40$ ). wt, wild-type; PhPI15s, transgenic plants expressing PhPII5.

because the sepals and petals of Phalaenopsis flowers are very similar and cannot be distinguished (Fig. 4).

Northern hybridizations are typically used to study gene expression but it is very difficult to use this technique to study floral development genes, because of the difficulty in isolating floral meristem mRNA without contamination from inflorescence mRNA. Thus, in situ hybridization analysis was used to analyze the PhPI15 expression pattern. PI is a B class organ identity gene that is first expressed in the floral meristematic domain, which will give rise to petals and stamens, and which can also be found in those cells that will give rise to the fourth whorl (Goto and Meyerowitz, 1994; Kramer et al., 1998). In our study, the transcript of PhPI15 was specifically localized in the inflorescence meristem (Fig. 6A). This indicates that PhPI15 is important for the initiation of floral development.
According to the classical ABC model, $\mathrm{B}$ group genes such as $A P 3$ and $P I$ have been thought to function in the control of petal and stamen development (Jack et al., 1992; Kramer et al., 1998). Studies of MADS-box gene function in monocot grasses indicated that this function of B group genes is conserved in rice (Kang et al., 1998; Kyozuka et al., 2000) and maize (Ambrose et al., 2000). The flowers of the grasses (Poaceae), however, are tiny and wind-pollinated, and quite different from the flowers in other flowering plant families. Studying the monocotyledonous tulip, Kanno (2003) proposed a modified ABC model, which may also apply to liliaceae. The expression patterns of PhPII5 fit nicely into the modified ABC model. PhPI15 may therefore be involved in the development of all floral organs. This gives us the opportunity to validate the classical $\mathrm{ABC}$ model in monocotyledonous plants.

In contrast to Arabidopsis, functional studies of MADS-box genes of orchids are limited. Here, we analyzed PhPI15 function by ectopic expression in tobacco plants. The $35 S: P h P I 15$ transgenic tobacco flowers showed obvious male-sterility. The observed phenotype was not entirely in accordance with previous reports of over-expression of $P I$ orthologues, such as $G L O$, in tobacco (Davies et al., 1996). They described a petaloidy sepal transgenic plant with male and female sterility. Although over expression of both PhPI15 and GLO led to male sterility, the transgenic plants containing $35 S:: G L O$ also produced a poorly developed carpel. This may be due to the fact that GLO is from the dicot plant Antirrhnium, whereas PhPI15 is from a monocotyledon. The orthologous genes in different classes may not have a completely conserved function. The phenotype of the $35 S:: P h P I 15$ transgenic plants described in this paper is male sterile (Fig. 8E-H). The length of the stamen (average $2.7 \mathrm{~cm}$ ) is much longer than that of carpel (average $3.2 \mathrm{~cm}$ ) (Fig. 8C, D); the average length of the wild-type stamen and carpel is $5.5 \mathrm{~cm}$ and $5.0 \mathrm{~cm}$, respectively, under the same condition. In addition, there is less pollen on the anther compared with the wild-type tobacco. By contrast, PeMADS6, the other PI-like gene cloned from Phalaenopsis equestris was reported to correlate with flower longevity and ovary development (Tsai et al., 2005). Further research will be required to determine whether PhPI15 is involved in the flower size and anther development.

A loss of function study of PhPII 5 needs to be carried out, and future studies need to define the role of PhPII5 in the development of Phalaenopsis flowers. The identification of PhPII5 is the first step toward the elucidation of the molecular mechanism of floral development in the orchid. This may lead to the potential to manipulate aspects of these processes to enhance floral development in Phalaenopsis.

Acknowledgment This study was supported by the National Natural Science Foundation of China No. 30570988, Science and Technology of Shanghai (2005) No. 1-1-2 and partly by Grant No. 05QMX 1408. 


\section{References}

Ambrose, B. A., Lerner, D. R., Ciceri, P. and Padilla C. M., Yanofsky, M. F. and Schmidt, R. J. (2000) Molecular and genetic analyses of the silkyl gene reveal conservation in floral organ specification between eudicots and monocots. Mol. Cells 5, 569579.

Bowman, J. L., Smyth, D. R. and Meyerowitz, E. M. (1991) Genetic interactions among floral homeotic genes of Arabidopsis. Development 112, 1-20.

Caliskan, M., Ozcan, B., Turan, C. and Cuming, A. C. (2004) Localization of germin genes and their products in developing wheat coleoptiles. J. Biochem. Mol. Biol. 37, 339-342.

Coen, E. S. and Meyerowitz, E. M. (1991) The war of the whorls: genetic interactions controlling flower development. Nature 353, 31-37.

Davies, B. and Schwarz-Sommer, Z. (1994) Control of floral organ identity by homeotic MADS-box transcription factors. Results Probl. Cell Differ. 20, 235-258.

Davies, B., Di Rosa, A., Eneva, T., Saedler, H. and Sommer, H. (1996) Alteration of tobacco floral organ identity by expression of combinations of Antirrhinum MADS-box genes. Plant J. 10, 663677.

Goto, K. and Meyerowitz, E. M. (1994) Function and regulation of the Arabidopsis floral homeotic gene PISTILLATA. Genes Dev. 8, 1548-1560.

Hama, E., Takumi, S., Ogihara, Y. and Murai, K. (2004) Pistillody is caused by alterations to the class-B MADS-box gene expression pattern in alloplasmic wheats. Planta 218, 712-720.

Jack, T., Brockman, L. L. and Meyerowitz, E. M. (1992) The homeotic gene APETALA3 of Arabidopsis thaliana encodes a MADS box and is expressed in petals and stamens. Cell 68, 683697.

Jackson, D. P. (1991) In situ hybridization in plants; in molecular plant pathology: a practical approach, Bowles, D. J., Gurr, S. J. and McPhereson, M. (eds.), pp. 163-174, Oxford University Press, Oxford, UK.

Jia, H., Chen, R., Cong, B., Cao, K., Sun, C. and Luo D. (2000) Characterization and transcriptional profiles of two rice MADSbox genes. Plant Sci. 155, 115-122.

Kang, H. G., Jang, S., Chung, J. E., Cho, Y. G. and An, G. (1997) Characterization of two rice MADS box genes that control flowering time. Mol. Cells 7, 559-566.

Kang, H. G., Jeon, J. S., Lee, S. and An, G. (1998) Identification of class $\mathrm{B}$ and class $\mathrm{C}$ floral organ identity genes from rice plants. Plant Mol. Biol. 38, 1021-1029.

Kanno, A., Saeki, H., Kameya, T., Saedler, H. and Theissen, G. (2003) Heterotopic expression of class B floral homeotic genes supports a modified ABC model for tulip (Tulipa gesneriana). Plant Mol. Biol. 52, 831-841.

Kim, S., Yoo, M. J., Albert, V. A., Farris, J. S., Soltis, P. S. and Soltis, D. E. (2004) Phylogeny and diversification of B-function MADSbox genes in angiosperms: evolutionary and functional implications of a 260-million-year-old duplication. Am. J. Bot. 91, 2102-2118.

Kramer, E. M., Dorit, R. L. and Irish, V. F. (1998) Molecular evolution of genes controlling petal and stamen development: duplication and divergence within the APETALA3 and
PISTILLATA MADS-box gene lineages. Gene 149, 765-783.

Kramer, E. M. and Irish, V. F. (1999) Evolution of genetic mechanisms controlling petal development. Nature 399, 144-148.

Kumar, S., Tamura, K. and Nei, M. (2004) MEGA3: integrated software for molecular evolutionary genetics analysis and sequence alignment. Brief Bioinform. 5, 150-163.

Kyozuka, J., Kobayashi, T., Morita, M. and Shimamoto, K. (2000) Spatially and temporally regulated expression of rice MADS box genes with similarity to Arabidopsis class $\mathrm{A}, \mathrm{B}$ and $\mathrm{C}$ genes. Plant Cell Physiol. 41, 710-718.

Lu, Z. X., Wu, M., Loh, C. S., Yeong, C. Y. and Goh, C. J. (1993) Nucleotide sequence of a flower-specific MADS box cDNA clone from orchid. Plant Mol. Biol. 23, 901-904.

Murray, M. G. and Thompson, W. F. (1980) Rapid isolation of high molecular weight plant DNA. Nucleic Acids Res. 8, 4321-4325.

Prakash, A. P. and Kumar, P. P. (2002) PkMADS1 is a novel MADS box gene regulating adventitious shoot induction and vegetative shoot development in Paulownia kawakamii. Plant J. 29, 141151.

Riechmann, J. L. And Meyerowitz, E. M. (1997) MADS domain proteins in plant development. Biol. Chem. 378, 1079-1101.

Rounsley, S. D., Ditta, G. S. and Yanofsky, M. F. (1995) Diverse roles for MADS box genes in Arabidopsis development. Plant Cell 7, 1259-1269.

Sommer, H., Beltran, J. P., Huijser, P., Pape, H., Lonnig, W. E., Saedle, H. and Schwarz-Sommer, Z. (1990) Deficiens, a homeotic gene involved in the control of flower morphogenesis in Antirrhinum majus: the protein shows homology to transcription factors. $E M B O ~ J . ~ 9,605-613$.

Song, I. J., Nakamura, T., Fukuda, T., Yokoyama, J., Ito, T., Ichikawa, H., Honiara, Y., Kameya, T. and Kanno, A. (2006) Spatiotemporal expression of duplicate AGAMOUS orthologues during floral development in Phalaenopsis. Dev. Genes Evol. 4, 113.

Theissen, G., Becker, A., Di Rosa, A., Kanno, A., Kim, J. T., Munster, T., Winter, K. U. and Saedler, H. (2000) A short history of MADS-box genes in plants. Plant Mol. Biol. 42, 115-149.

Tsai, W. C., Kuoh, C. S., Chuang, M. H., Chen, W. H. and Chen, H. H. (2004) Four $D E F$-like MADS box genes displayed distinct floral morphogenetic roles in Phalaenopsis orchid. Plant Cell Physiol. 45, 831-844.

Tsai, W. C., Lee, P. F., Chen, H. I., Hsiao, Y. Y., Wei, W. J., Pan, Z. J., Chuang, M. H., Kuoh, C. S., Chen, W. H. and Chen, H. H. (2005) PeMADS6, a GLOBOSA/PISTILLATA-like gene in Phalaenopsis equestris involved in petaloid formation, and correlated with flower longevity and ovary development. Plant Cell Physiol. 46, 1125-1139.

Weigel, D. and Meyerowitz, E. M. (1994) The ABCs of floral homeotic genes. Cell 78, 203-209.

Xu, Y., Teo, L. L., Zhou, J., Kumar, P. P. and Yu, H. (2006) Floral organ identity genes in the orchid Dendrobium crumenatum. Plant J. 46, 54-68.

Yang, Y., Fanning, L. and Jack, T. (2003) The K domain mediates heterodimerization of the Arabidopsis floral organ identity proteins, APETALA3 and PISTILLATA. Plant J. 33, 47-59.

Yu, H. and Goh, C. J. (2000) Identification and characterization of three orchid MADS-box genes of the AP1/AGL9 subfamily during floral transition. Plant Physiol. 123, 1325-1336. 